\title{
The different effects of sodium bicarbonate and aluminium hydroxide on the absorption of indomethacin in man
}

\author{
J. C. Garnham \\ M.B., B.S.
C. M. KAYE
Ph.D.

\author{
T. KASPI \\ V. M. S. OH \\ M.R.C.P.
}

Department of Clinical Pharmacology, St Bartholomew's Hospital, London EC1A 7BE

\begin{abstract}
Summary
The influence of oral sodium bicarbonate and aluminium hydroxide on the absorption of indomethacin has been studied in normal volunteers. While sodium bicarbonate appeared to increase indomethacin absorption, aluminium hydroxide markedly reduced both the rate and extent of absorption. The buccal absorption of indomethacin over the pH range 5-9 was also studied in normal volunteers, and showed that the percentage absorption increased markedly as the $\mathrm{pH}$ was reduced. The clinical importance both of $\mathrm{pH}$ partition and of adsorption are discussed in the context of antacid interactions. It is concluded that caution must be exercised when prescribing an antacid with other orally-administered drugs.
\end{abstract}

\section{Introduction}

Various anti-inflammatory agents such as aspirin and indomethacin are frequently taken over the same period by the same patient (Mason et al., 1975). Furthermore, antacids are sometimes added to the therapeutic regimen to relieve the dyspepsia caused by such drugs. The effect of these compounds on each other has been the subject of several studies (Champion et al., 1972; Jeremy and Towson, 1970; Garnham et al., 1975).

Garnham et al. (1973) suggested that not only the nature of the companion drug, but also the relative timing of the administration of the two drugs might be important, furthermore 'concurrent' is not necessarily the same as 'simultaneous' administration of a drug.

In a recent paper, Brooks et al. (1975) examined the effect of the concurrent administration of soluble aspirin on plasma indomethacin levels. They used a partly buffered aspirin with a formulation different from the aspirin formulations used in the other studies (Champion et al., 1972; Jeremy and Towson, 1970; Garnham et al., 1975). They achieved similar results to those of Champion et al. in 1972.

Reprint requests to Dr V. Oh.
Garnham et al. (1975) postulated that it was the riv addition of the antacid to aspirin and the simuls taneous administration of the buffered aspirin that $\vec{N}$ increased the rate of absorption of indomethacin found by the present authors. This paper describes? studies to evaluate the passage of indomethacin? alone-a weak acid-across mucous membranes by $\vec{z}$ the buccal absorption test (Becket and Triggs, 1967) at different $\mathrm{pHs}$ and the absorption of indomethacins into the blood stream after oral administration alone and together with two different antacids.

\section{Subjects and methods}

The influence of two antacids on the absorpt of indomethacin (Indocid) was studied in six healthyo volunteers (one female and five male) aged 19-310 years none of whom had a history of gastrointestina迟 disease. The three treatments (indomethacin $50 \mathrm{mg} \overrightarrow{\sigma_{0}}$ plus sodium bicarbonate $1400 \mathrm{mg}$ as an aqueous 3 solution, and indomethacin $50 \mathrm{mg}$ plus aluminium? hydroxide $700 \mathrm{mg}$ as an aqueous suspension and? indomethacin $50 \mathrm{mg}$ alone) were administeredô orally at weekly intervals according to a balanced, randomized design. On the fourth week all sixo subjects received a further treatment (indomethacin: $50 \mathrm{mg}$ plus sodium bicarbonate tablets $600 \mathrm{mg}$ ). On each occasion the subjects had fasted overnight and venous blood samples were obtained before, and윽 at $0 \cdot 5,1,1 \cdot 5,2,2 \cdot 5,3,4,6$ and $8 \mathrm{hr}$ after dosing. Plasma concentrations of indomethacin were measured fluorimetrically by a method based on that described by Hvidberg, Lausen and Jansen (1972). Student's paired $t$-test was used for statistical analysis.

The buccal absorption of indomethacin over the pH range 5-9 was studied in eight healthy volunteerso according to the method of Becket and Triggs $\Phi$ (1967). The indomethacin remaining in the diluted $\stackrel{?}{+}$ saliva was determined by ultra-violet spectrophotometry after using the double extraction method of $\frac{\vec{\Phi}}{\mathbb{D}}$ Hvidberg et al. (1972). 


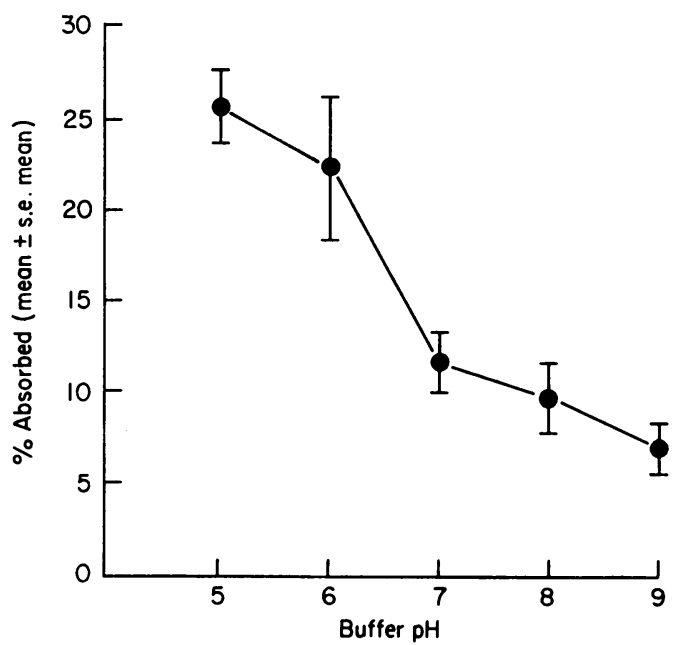

FIG. 1. The influence of $\mathrm{pH}$ on the buccal absorption of indomethacin.

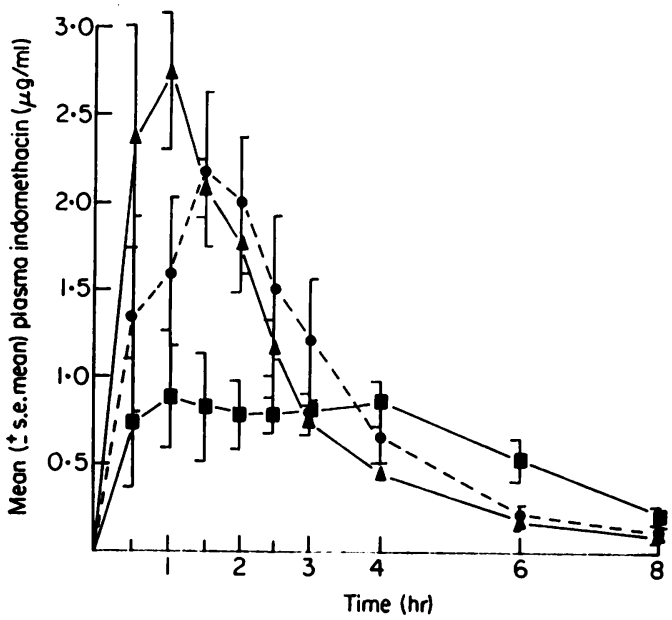

FIG. 2. Plasma levels of indomethacin in six healthy volunteers after $50 \mathrm{mg}$ oral indomethacin alone (-- -0$)$, with sodium bicarbonate $(\mathbf{\Lambda}-\mathbf{\Lambda})$ and with aluminium hydroxide $(\square-\square)$.

\section{Results}

The mean ( \pm s.e. mean) results of the eight volunteers who took part in the buccal absorption study are shown in Fig. 1. As predicted from theoretical considerations the absorption of indomethacin decreased as the $\mathrm{pH}$ was increased from 5 to 9 . The mean ( \pm s.e. mean) results of the six volunteers who took part in the study involving the two antacids are shown in Figs 2 and 3. The mean plasma levels shown in Fig. 2 demonstrate that aluminium hydroxide reduces the rate of absorption of indomethacin, the differences between the corresponding

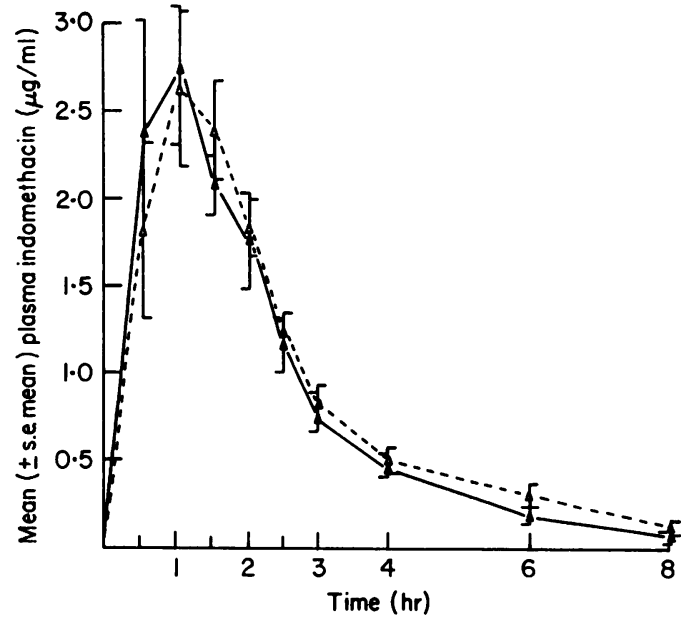

Fig. 3. Plasma levels of indomethacin in six healthy volunteers after $50 \mathrm{mg}$ oral dose with sodium bicarbonate in tablet form $(\triangle---\Delta)$ and in aqueous solution $(\mathbf{\Lambda}-\mathbf{\Lambda})$.

plasma levels being statistically significant at 1.5 and $2 \mathrm{hr}$. It would appear that sodium bicarbonate increases the rate of absorption of indomethacin leading to somewhat higher and earlier peak plasma levels although, owing to inter-individual variation, the differences between the corresponding levels at 30 and 60 min just failed to attain statistical significance. However, Fig. 2 clearly shows that the two antacids, sodium bicarbonate and aluminium hydroxide, have markedly different effects on the absorption of indomethacin, the differences between the corresponding plasma levels being statistically significant at $0.5,1,1.5,2,6$ and $8 \mathrm{hr}$. Figure 3 compares the effects of sodium bicarbonate taken in solution or as tablets on the absorption of indomethacin. As can be seen, the mean plasma level profiles are almost identical and reflect the very little intra-subject variation found, under similar conditions.

\section{Discussion}

The buccal absorption test showed that, at different $\mathrm{pHs}$, the passage of indomethacin across a mucous membrane in an uncomplicated situation is exactly what would be predicted from the $\mathrm{pH}$ partition hypothesis, i.e. at low pHs where there is less dissociation, absorption is greatest (see Fig. 1). However, the rest of the data show how dangerous it is to extrapolate from the simple situation in the mouth with the drug in solution to the complicated situation further along the gastro-intestinal tract with the drug in a capsule. One might expect antacids to decrease absorption of indomethacin and apparently aluminium hydroxide does that. However, there is a 
large difference between the effect of aluminium hydroxide and that of sodium bicarbonate (see Fig. 2) which is significant at $0.5,1,1.5,2,6$ and $8 \mathrm{hr}$. Whereas aluminium hydroxide decreases the rate of absorption, sodium bicarbonate, if anything, increases the rate of absorption of indomethacin. It is possible that the aluminium hydroxide adsorbs the indomethacin, or that indomethacin might form an insoluble aluminium salt derived from the soluble aluminium salts generated by the interaction of the hydroxide with the gastric acid. Khalil (1974) has shown that a suspension of $6.2 \%$ aluminium hydroxide dried gel produced a marked reduction in the digoxin content from a paediatric elixir, as did magnesium trisilicate. He also showed (El-Masry and Khalil, 1974) that atropine and hyoscine are adsorbed by magnesium trisilicate and belladonna mixture. Ambre and Fischer (1973) found that while aluminium hydroxide gel decreased the absorption cf bishydroxycoumarin, magnesium hydroxide increased it.

It is sometimes said that gastric activity is such that large amounts of antacids must be given to have any effects. Kuna (1964) showed that six out of every twelve normal subjects had gastric juice with a $\mathrm{pH}$ of 5.5 or higher. In addition, 1,552 recordings of the pH values in 312 subjects showed only $19 \%$ to be in the 'free acid' $\mathrm{pH}$ range while $45 \%$ were in a $\mathrm{pH}$ range of 3.5-6.0.

Levin, Kirsner and Palmer (1951) in morning aspirations found that $45 \%$ of normal males and $60 \%$ of normal females had periods of 'anacidity'. James and Pickering (1949) found that sixteen of twenty-three patients showed $\mathrm{pH}$ values near neutral during sleep. Small amounts of antacids under these conditions could thus have marked effects on the pH. Garnham et al. (1975) showed that whereas one Bufferin tablet had only a slight effect on $50 \mathrm{ml} \mathrm{N} / 10$ hydrochloric acid, with $\mathrm{N} / 100$ hydrochloric acid an equilibrium of about pH 6 was obtained. Although the administration of acids or alkalis has been claimed to affect not only absorption but metabolism and/or excretion (Hurwitz and Sheenan, 1971; Andrews and Cornatzer, 1944; Hurwitz, 1971) as well, the effects seen in this experiment occur so early that it is likely they are predominantly due to effects on absorption. This is similar to the studies by Segre et al. (1974).

It is clear, therefore, that caution must be exercised in the interpretation of comments such as that by Emori et al. (1973) 'Antacid delays by $50 \%$ but does not diminish peak levels' (of indomethacin by aluminium hydroxide gel). Impressions gained from the literature of the effect of one class of drugs upon another may also have to be revised, for example, that antacids decrease the absorption of coumarin anticoagulants (Anonymous, 1967; Azarnoff and
Hurwitz, 1970; Hussar, 1970; McCallister, Chin and Lach, 1970).

When predicting the possible interaction between antacid preparations and other drugs, at least six possible factors should be considered:

(1) The solubility of the parent compound? Acidic drugs are more soluble at higher pHs and dissolution may thus be favoured.

(2) Ionization increases, in the case of an acidic compound, as the $\mathrm{pH}$ rises, thus reducing its passage across a mucous membrane, according to the $\mathrm{pH}$ partition hypothesis.

(3) The adsorbing or chelating ability of the antacid preparation.

(4) Physical interference, such as the effect of viscous gel on the rate of disintegration of the drug's. formulation.

(5) The buffering capacity of some antacids isं higher than that of others.

(6) The rate of gastric emptying may vary a different gastric $\mathrm{pH}$ values.

\section{Acknowledgments}

We thank Professor Paul Turner for helpful discussion in the preparation of this paper.

\section{References}

AMBRE, J.J. \& Fischer, L.J. (1973) Effect of coadministration of aluminium and magnesium hydroxide on absorptiono anticoagulants in man. Clinical Pharmacology and Thera:peutics, 14, 231.

ANDrews, J.C. \& Cornatzer, W.E. (1944) The effect of acid and alkali on the absorption and metabolism of quinine? Journal of Pharmacology and Experimental Therapeutics, 82, 261.

ANONYMOUs (1967) Drug interactions that can affect you patients. In: Patients Care, pp. 1-23. Miller and Fink Publishing Corp., New York.

AzarnofF, D. \& HURwitz, A. (1970) Drug interactions. In? Pharmacology for Physicians, pp. 1-7. W. B. Saunders Co. Philadelphia.

BeCKeT, A.H. \& Triggs, E.J. (1967) Buccal absorption of basic drugs and its application as an in vivo model on passive drug transfer through lipid membranes. Journat; of Pharmacy and Pharmacology, 19 (Suppl.), 31.

Brooks, P.M., Walker, J.J., Bell, M.A., Buchanan, W.W\& RHYMER, A.R. (1975) Indomethacin-aspirin interaction a clinical appraisal. British Medical Journal, 3, 69.

Champion, G.D. Paulus, H.E., Mongan, E., Okun, R. Pearson, C.M. \& Sarkissan, E. (1972) The effect of aspirin on serum indomethacin. Clinical Pharmacology and Therapeutics, 13, 239.

El-MasRY, S. \& KHALIL, S.A.H. (1974) Adsorption of atropine and hyoscine on magnesium trisilicate. Journal of Pharmacy and Pharmacology, 26, 243.

Emori, W., Paulus, H.E., Bluestone, R. \& Pearson, C.MO (1973) The pharmacokinetics of indomethacin in serum $N$ Clinical Pharmacology and Therapeutics, 14, 134.

Garnham, J.C., Raymond, K., ShotTon, E. \& TuRner, Pर (1973) The availability of indomethacin and the effect of concurrent administration of aspirin on blood levels in man $\bar{D}$ Abstract from Fédération Internationale Pharmaceutiquẹ Meeting, Stockholm, 3-7 September.

GarnhaM, J.C., RaYmond, K., ShotTen, E. \& TuRner, P० (1975) The effect of buffered aspirin on plasma indometh $\overrightarrow{\mathbb{D}}$ acin. European Journal of Clinical Pharmacology, 8, 107. 
Hurwitz, A. (1971) The effects of antacids on gastrointestinal drug absorption. II. Effect of sulphadiazine and quinine. Journal of Pharmacology and Experimental Therapeutics, $179,485$.

Hurwitz, A. \& Sheenan, M.B. (1971) The effects of antacids on the absorption of orally administered pentobarbital in the rat. Journal of Pharmacology and Experimental Therapeutics, 179, 124.

Hussar, D. (1970) Oral anticoagulants-their interactions. Journal of the American Pharmaceutical Association, 10, 78.

Hvidberg, E., LAusen, H.H. \& JANSEN, J.A. (1972) Indomethacin: plasma concentrations and protein binding in man. European Journal of Clinical Pharmacology, 4, 119.

James, A.H. \& Pickering, G.W. (1949) The role of gastric acidity in the pathogenesis of peptic ulcer. Clinical Science, 8, 181.

JEREMY, R. \& TowsON, J. (1970) Interaction between aspirin and indomethacin in the treatment of rheumatoid arthritis. Medical Journal of Australia, 2, 127.
KHALIL, S.A.H. (1974) The uptake of digoxin and digitoxin by some antacids. Journal of Pharmacy and Pharmacology, 26, 961 .

KunA, S. (1964) The pH of gastric juice in the normal resting stomach. Archives internationales de pharmacodynamie et de thérapie, 152, 79.

Levin, E., Kirsner, J.B. \& Palmer, W.L. (1951) Benign gastric ulcer with apparent achlorhydria. Gastroenterology, $17,414$.

Mason, D.I.R., Brooks, P.M., Lee, P., Kennedy, A.C. \& WATSON-BUCHANAN, W. (1975) In-patient prescribing in a rheumatic diseases centre. Scottish Home and Health Department Bulletin, 33, 72.

McCallister, J., Chin, T. \& LaCh, J. (1970) Diffuse reflectance studies of solid-solid interactions. IV. Interaction of bishydroxycoumarin, furosemide and other medicinal agents with various adjuvants. Journal of Pharmaceutical Sciences, 59, 1286.

Segre, E.J., Chaplin, M., Forchielli, E., Runkel, R. \& Sevelius, H. (1974) Naproxen-aspirin interactions in man. Clinical Pharmacology and Therapeutics, 15, 374. 